\title{
Технические аспекты публикации на нескольких языках - как правильно связать DOI
}

\author{
Александр Бирюков ${ }^{1,2[0000-0002-4925-9131]}$ и Алексей В. Скалабан ${ }^{3[0000-}$ \\ $0002-3350-4454]$ \\ ${ }^{1}$ Springer Nature, Гейдельберг, Германия \\ 2 Российский университет дружбы народов, Москва, РФ \\ ${ }^{3}$ Некоммерческое партнёрство «Национальный электронно-информационный \\ консорциум»
}

\begin{abstract}
Аннотация. Статья призвана оспорить утверждение "объединить же ссылки на версии одной и той же статьи в журналах разных издательств не представляется возможным (DOI пока эту задачу не решает)".

Мы рассматриваем проблему публикации на нескольких языках и связанные с этим библиометрические и этические проблемы. Текущие практики включают в себя а) использование одного DOI одним издателем, б) использование разных DOI одним издателем, в) использование разных DOI разными издателями. Существующие решения для связи публикаций на нескольких языках, такие как Math-Net.Ru решают рассмотренные проблемы только частично. Проанализировав плюсы и минусы различных решений, мы предлагаем решение связывания DOI различных версий статьи с помощью нового механизма Crossref и рассмотрим как этот механизм используется международными и российскими журналами. Мы надеемся, массовый переход журналов на использование этого механизма не только исключит этические проблемы, но и поможет международным наукометрическим базам организовать правильный подсчет цитат.
\end{abstract}

Ключевые слова: переводные журналы, библиометрический анализ, наукометрия, индексы цитирования.

\section{1 Введение}

В [1] затронута проблема издания двуязычных (переводных) журналов. Автор справедливо замечает, что если русскоязычный журнал издается на английском языке другим издательством, как происходит с журналами, которые переводят и издают Pleiades Publishing или Springer, то ссылки (цитаты) на статьи делятся на две версии: оригинальную ${ }^{1}$ и переводную. Автор также подчеркивает

\footnotetext{
1 Здесь и далее, правильнее было бы использовать термины «оригинальная» и «переводная» версии, так как некоторые журналы Springer переводятся с украинского (см. Ukrainian Mathematical journal, https://www.springer.com/journal/11253), а некоторые
} 
проблемы учета ссылок на статьи, если одна из версий не индексируется в международных наукометрических базах данных (МНБД) и замечает, что «объединить же ссылки на статьи двух журналов разных издательств не представляется возможным (DOI пока эту задачу не решает)».

Проблема учета ссылок ведёт к потерям в учете цитирования статей из российских журналов и некорректным показателям цитируемости публикаций в них. Как показано авторами в [2] на нескольких примерах, авторы и статьи могут терять до 200\% по библиометрическим показателям, таким как, среднее число цитат на статью, индекс Хирша.

Тешейра да Силва [3] рассматривает этические вопросы публикации на нескольких языках. Автор замечает, что если несколько источников публикуют одни и те же данные, текст, идеи, концепции, методологию, анализ, и при этом четко ссылаются друг на друга, то редакторы, рецензенты и читатели оказываются проинформированными, что эти материалы уже были опубликованы на другом языке. В этом случае уменьшается риск этических нарушений. В случае же, когда такая дублирующая публикация происходит без ссылки на материал на другом языке, это является этическим нарушением. В статье упоминается пример сотрудничества Российской Академии Наук (PAH), Pleiades Publishing, и Springer Nature по переводу и распространению английских версий журналов РАН как пример передовой практики, т.к. про публикацию на двух языках известно заранее и английская версия статьи содержит информацию про то, что она переведена с русского.

В нашей статье мы хотим рассмотреть некоторые существующие практики кросс-ссылок оригинальной и переводной версий одной и той же статьи, критически проанализировать их с точки зрения упомянутых библиометрических и этических проблем, а также описать решение, основывающееся на новых возможностях Crossref. Хотя решение еще не используется МНБД, мы надеемся, что издатели могут начать его использовать и МНБД со временем присоединяться. Это увеличит видимость публикаций не (только) на английском языке в международной науке.

журналы Eco-Vector (см. . Однако, поскольку большинство журналов переводятся с русского 


\section{2 Существующие практики связывания версий статьи на нескольких языках}

В этой секции мы рассмотрим примеры связывания ссылок на русско- и англо- язычные версии статей из нескольких журналов.

\section{1 Использование одного и того же DOI одним издателем}

Это возможно, если русская и английская версия издается одним издателем. В данном случае, печатная и онлайн версия журнала «Фармация и фармакология» технически зарегистрированы в ISSN peестре $^{2}$ как один журнал, издаваемый Пятигорским медикофармацевтическим институтом. На сайте журнала предлагаются варианты цитирования на английском и русском, с одним и тем же DOI (Рис. 1).

\section{Аля цитирования:}

Корокин М.В., Солдатов В.О., Титце А., Голубев И.В., Белых А.Е., Кубекина М.В., Пученкова О.А., Денисюк Т.А., Гуреев В.В., Покровская Т.Г., Гудырев О.С., Жученко М.А., Затолокина М.А., Покровский М.B. 11-аминокислотный пептид, имитирующий структуру а-спирали b эритропоэтина, улучшает функцию эндотелия, но стимулирует тромбообразование у крыс. Фармация и фармакология. 2019;7(6):312-320. https://doi.org/10.19163/2307-9266-2019-7-6-312-320

\section{For citation:}

Korokin M.V., Soldatov V.O., Tietze A.A., Golubev M.V., Belykh A.E., Kubekina M.V., Puchenkova O.A., Denisyuk T.A., Gureyev V.V., Pokrovskaya T.G., Gudyrev O.S., Zhuchenko M.A., Zatolokina M.A., Pokrovskiy M.V.11-amino acid peptide imitating the structure of erythropoietin a-helix b improves endothelial function, but stimulates thrombosis in rats.. Pharmacy \& Pharmacology. 2019;7(6):312-320. (In Russ.) https://doi.org/10.19163/2307-9266-2019-7-6-312-320

Рис. 1. Пример статьи из журнала Фармация и фармакология (Pharmacy \& pharmacology): https://doi.org/10.19163/2307-9266-2019-7-6-312-320.

\section{2 Использование разных DOI одним издателем}

\footnotetext{
2 https://portal.issn.org/resource/ISSN/2413-2241
} 
В этом примере мы рассмотрим журнал «Успехи Физики» из [2]. Судя по DOI префиксу и веб-сайту журнала, русская ${ }^{3}$ и английская версия «Physics-Uspekhi ${ }^{4} »$ издается самим журналом. Английская версия распространяется издательствами IOP Publishing и Turpion. Рис. 2 показывает, как русская и английская версии одной и той же статьи представлены на веб-сайтах журнала и отображаются в тексте статьи. В данном случае, русская и английская версия имеют различные сайты, выходные данные и DOI с одинаковым издательским префиксом (10.3367). Несмотря на это, и русская и английская версии ссылаются друг на друга (последняя и первая страницы статьи, соответственно).

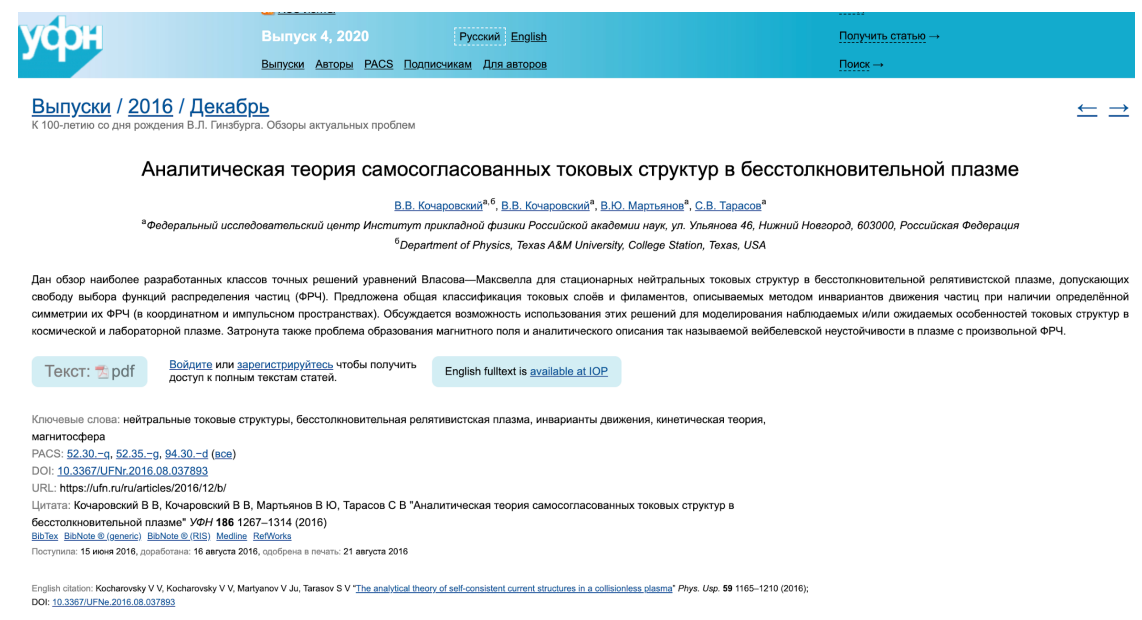

\footnotetext{
${ }^{3}$ https://portal.issn.org/resource/ISSN/1996-6652
}

${ }^{4}$ https://portal.issn.org/resource/ISSN/1468-4780 


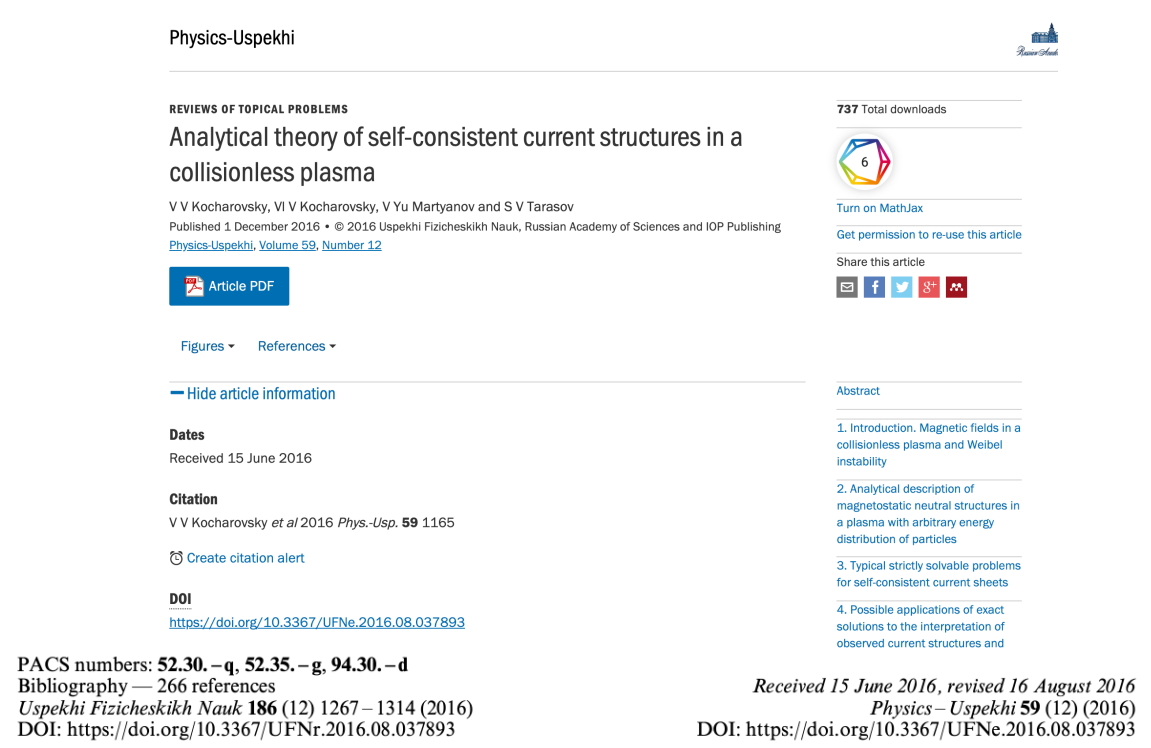

Received 15 June 2016, revised 16 August 2016

Uspekhi Fizicheskikh Nauk 186 (12) $1267-1314$ (2016)

DOI: https://doi.org/10.3367/UFNr.2016.08.037893

Translated by Yu V Morozov; edited by A Radzig

Рис. 2. Пример статьи из журнала Успехи физических наук (Physics-Uspekhi): https://doi.org/10.3367/UFNr.2016.08.037893 и https://doi.org/10.3367/UFNe.2016.08.037893.

\section{3 Использование разных DOI разными издателями - журнал РАН}

В этом примере мы также рассмотрим журнал из [2]. Это «Журнал неорганической химии ${ }^{5} \gg$ издаваемый на русском ИКЦ "Академкнига", английская версия которого «Russian journal of inorganic chemistry ${ }^{6} »$ публикуется Pleiades Publishing и распространяется Springer Nature. В данном случае, русская и английская версия имеют различные сайты, выходные данные, и DOI, у которых даже префиксы отличаются (Рис. 3). Английская версия ссылается на русскую в колонтитулах.

\footnotetext{
${ }^{5}$ https://portal.issn.org/resource/ISSN/0044-457X

${ }^{6} \mathrm{https} / / /$ portal.issn.org/resource/ISSN/1531-8613
} 


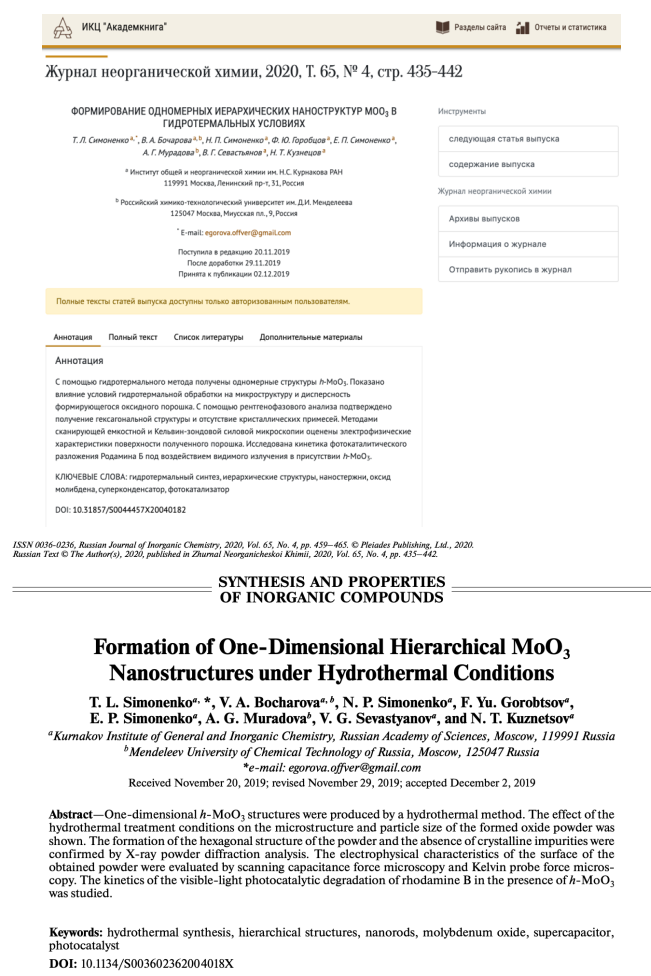

Рис. 3. Пример статьи из Журнала неорганической химии (Russian journal of inorganic chemistry): http://doi.org/10.31857/S0044457X20040182 и http://doi.org/10.1134/S003602362004018X.

\section{4 Использование разных DOI разными издателями - не журнал РАН}

В этом примере мы рассмотрим журнал «Новые Огнеупоры ${ }^{7}$ » издаваемый на русском ООО «Функциональные наноматериалы», английская версия которого «Refractories and Industrial Ceramics ${ }^{8}$ » публикуется и распространяется Springer. Как и в предыдущем примере, русская и английская версия имеют различные сайты, выходные данные, и DOI, у которых префиксы отличаются (Рис. 4). Английская версия ссылается на русскую в колонтитулах и в «Additional Information ${ }^{9} »$.

\footnotetext{
7 https://portal.issn.org/resource/ISSN/1683-4518

$8 \mathrm{https}$ ///portal.issn.org/resource/ISSN/1573-9139

9 https://link.springer.com/article/10.1007/s11148-019-00372-4\#additional-information
} 


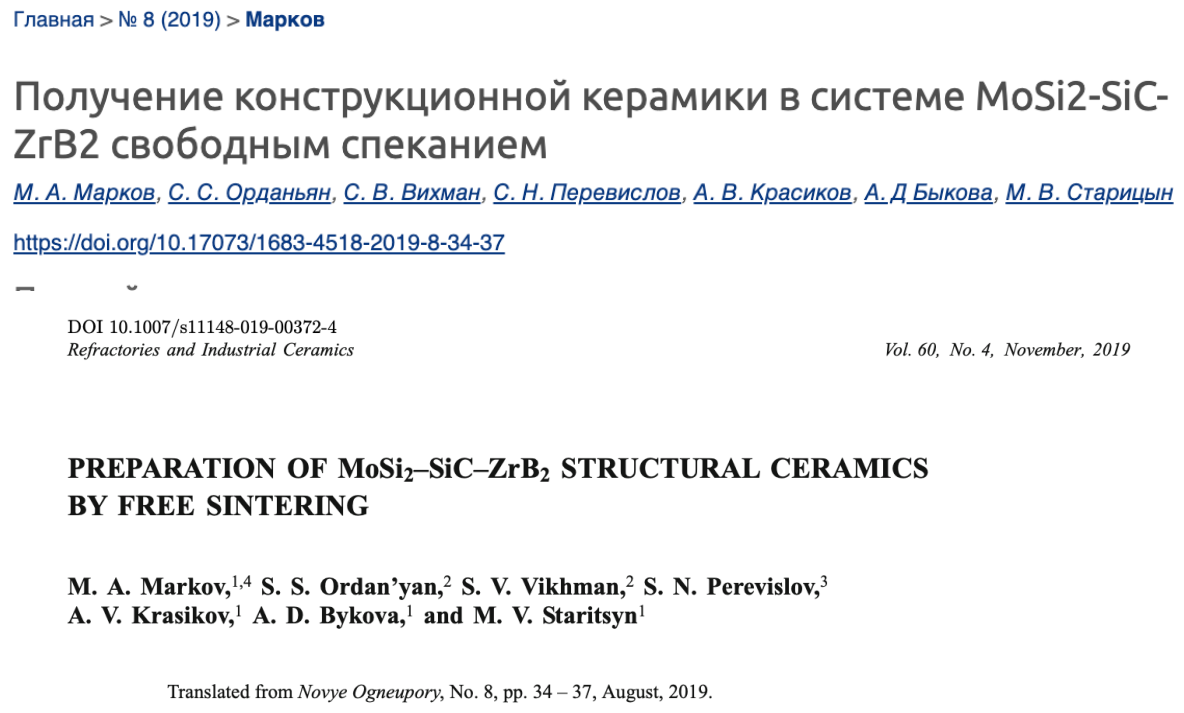

\section{Additional information}

Translated from Novye Ogneupory, No. 8, pp. 34-37, August, 2019.

Рис. 4. Пример статьи из журнала Новые Огнеупоры (Refractories and Industrial Ceramics): https://doi.org/10.17073/1683-4518-2019-8-34-37 и https://doi.org/10.1007/s11148-019-00372-4.

\section{5 Сведение ссылок вне сайтов журнала}

Некоторые сайты журналов, например сайт упомянутого в 2.2 «Успехи физических наук» ведут таблицы соответствия между русской и английской версией статьи. Такие таблицы позволяют объединить статистику ссылок на обе версии статьи. Насколько нам известно, одним из самых распространённых примером ведения такого соответствия является общероссийский математический портал Math-Net.Ru [4], который создан и развивается Математическим институтом им. В. А. Стеклова PAH. Math-Net.Ru собирает систематическую информацию о всех российских (и советских) математических (и многих физических) журналах с момента их основания до наших дней. В частности, Рис. 5 показывает статью (используемую в качестве примера в [2]) из журнала «Успехи физических наук». Страница не только указывает 
DOI обеих версий, она позволяет посмотреть количество цитат на каждую из версий в МНБД Dimensions и Google Scholar.

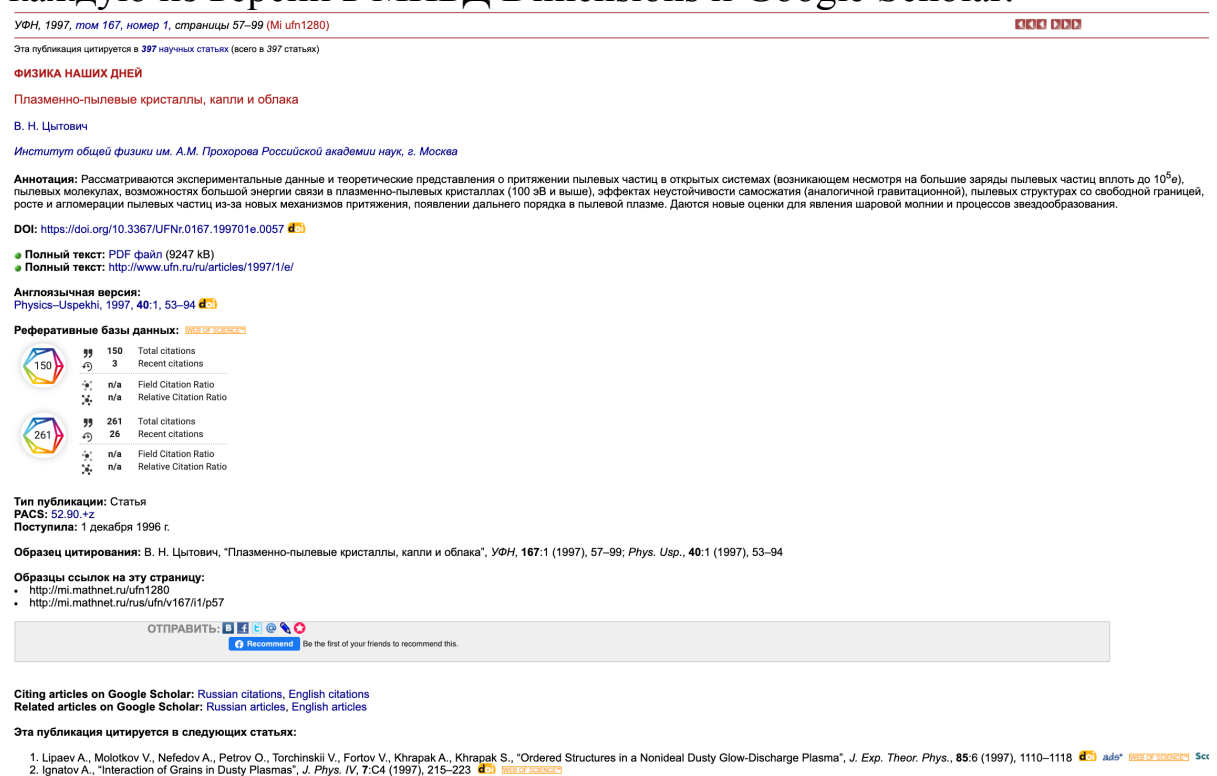

Рис. 5. Пример статьи из журнала Успехи физических наук (Physics-Uspekhi): http://www.mathnet.ru/php/archive.phtml?wshow=paper\&jrnid=ufn\&paperid=1280.

\section{6 Критический анализ примеров}

Рассмотрим варианты 2.1-2.4 в контексте проблем, которые мы описали во Введении, а именно как в каждом случае 1) происходит учет цитирования и 2) присутствует ссылка на другую версию, чтобы избежать этических нарушений.

Таблица 1. Анализ примеров 2.1-2.4 с точки зрения учета цитат и ссылки версий друг на друга.

\begin{tabular}{|c|c|c|c|c|c|c|}
\hline \multirow[t]{2}{*}{ Журнал } & \multirow{2}{*}{$\begin{array}{l}\text { Учет цитирования } \\
\text { обеих версий }\end{array}$} & \multicolumn{2}{|c|}{ Сайт журнала } & \multicolumn{2}{|c|}{ Текст статьи } & \multirow{2}{*}{$\begin{array}{l}\text { Переводчик } \\
\text { указан }\end{array}$} \\
\hline & & $\begin{array}{l}\mathrm{Ru}- \\
>\text { En }\end{array}$ & $\begin{array}{l}\text { En- } \\
>\mathrm{Ru}\end{array}$ & $\begin{array}{l}\text { Ru- } \\
>\text { En }\end{array}$ & $\mathrm{En}->\mathrm{Ru}$ & \\
\hline $\begin{array}{l}\text { Фармация и } \\
\text { фармакология } \\
\text { (2.1) }\end{array}$ & $\begin{array}{l}\text { Возможен через } \\
\text { DOI }\end{array}$ & + & + & + & + & + \\
\hline $\begin{array}{l}\text { Успехи } \\
\text { физических } \\
\text { наук (2.2) }\end{array}$ & $\begin{array}{l}\text { Возможен через } \\
\text { таблицу } \\
\text { соответствия }\end{array}$ & + & + & + & + & + \\
\hline Журнал & Соответствие DOI & - & - & - & + & + \\
\hline $\begin{array}{l}\text { неорганической } \\
\text { химии (2.3) }\end{array}$ & нужно определять & & & & & \\
\hline
\end{tabular}




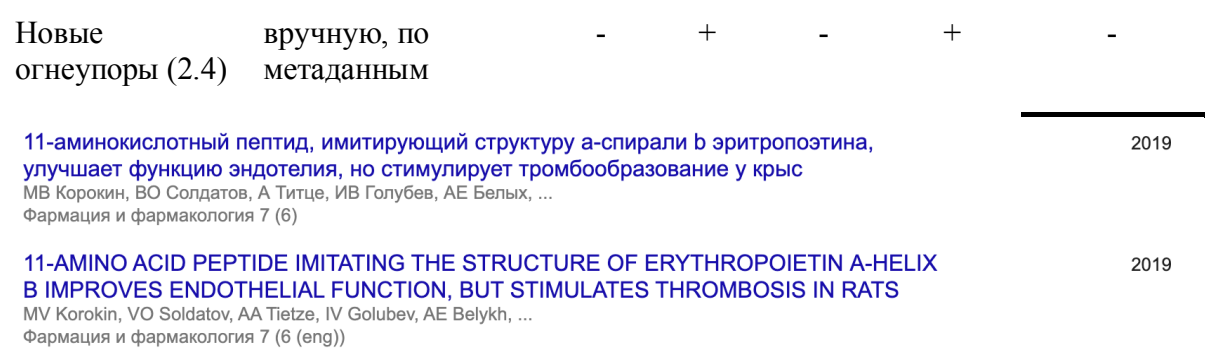

Рис. 6. Пример дублирования статьи из журнала Фармация и фармакология в профиле Google Scholar M.B. Корокина:

https://scholar.google.com/citations?hl=en\&user=CjQ0Z1kAAAAJ\&view_op=list_works\&sort by=pubdate

Результаты анализа представлены в Таблице 1. Поскольку во всех примерах мы имеем дело с метаданными для двух версий (русская и английская), полностью избежать «дублирования» статей невозможно. Даже в, казалось бы, идеальном примере 2.1 Google Scholar учитывает две публикации - см. Рис. 6. Поэтому в анализе мы сосредоточились на вопросе «Как можно свести ссылки, если мы хотим посчитать общее число цитат всех версий статьи?». По поводу этических нарушений мы обращали внимание на то ссылаются ли веб сайты и полные тексты (хотя бы в колонтитуле) одной из версий на вторую (+ если ссылается и - если не ссылается). Последняя колонка показывает упоминается ли переводчик на сайте или в полном тексте английской версии.

Из результатов анализа видно, что корректный учет цитирования возможен в примерах 2.1 и 2.2, в то время как в 2.3 и 2.4 необходимо сначала установить соответствие между DOI обеих версий - ни вебсайт, ни полный текст статьи это не делает. Но по крайней мере, это возможно, т.к. английские статьи упоминают метаданные русских версий. Как показано в примере 2.5 , сервис MathNet.Ru облегчает эту задачу. Однако, этот сервис охватывает только математические и физические журналы.

Во всех примерах отсутствуют этические нарушения, и, что приятно заметить, все, кроме примера 2.4 указывают фамилию переводчика.

\section{3 Кросс-ссылки 2.0 с использованием Crossref}

Как рассмотрено в предыдущем разделе, «свести» показатели цитирования различных версий статьи можно либо используя один 
DOI либо через таблицу соответствий. Первый вариант не всегда возможен, а во втором варианте возможны различные опции ведения такой таблицы. В этом разделе мы описываем третий вариант «связывания» DOI различных версий статьи - через стандартный механизм Crossref.

Crossref предоставляет возможность указать отношение (relationship) между различными научными объектами ${ }^{10}$. Такое отношение может устанавливать соответствие между журнальными статьями, опубликованными на разных языках и с разными DOI. Crossref предлагает указывать это отношение при (или после) регистрации второго DOI, то есть переводная версия ссылается на оригинал и декларирует, что является переводом.

<program xmlns="https://www.crossref.org/relations.xsd" > $<$ related_item $>$

$<$ description $>$ Russian translation of an article</description $>$

$<$ intra_work_relation relationship-type $=$ "isTranslationOf" identifiertype="doi" >10.7717/peerj.4375</intra_work_relation >

$<$ /related_item $>$

$</$ program $>$

Relation 1

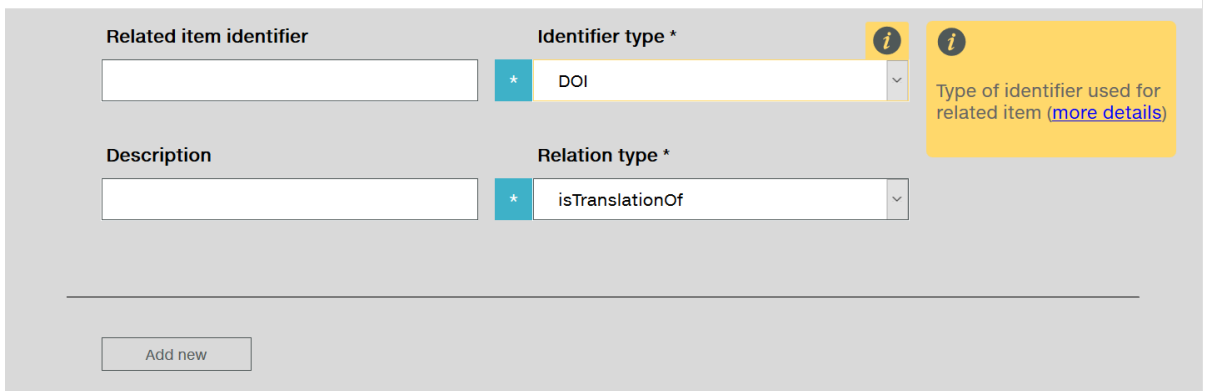

Рис. 7. Примеры установления ссылки между переводом и оригиналом в XML и в инструменте Metadata Manager.

Рис. 7 показывает, как устанавливать ссылку между переводом и оригинальной версией в XML (реальный пример) и через инструмент Metadata Manager. Рис. 8 показывает на абстрактном

${ }^{10}$ Crossref / Content registration / Structural metadata. https://www.crossref.org/education/content-registration/structural-metadata/\#00047. Доступ: 26 мая 2020. 
примере как издатель переведенной статьи может использовать отношение hasTranslation, чтобы установить связь между оригинальной версией и переводом ${ }^{11}$. Рис. 9 показывает, как метаданные выглядят в формате JSON в API Crossref.

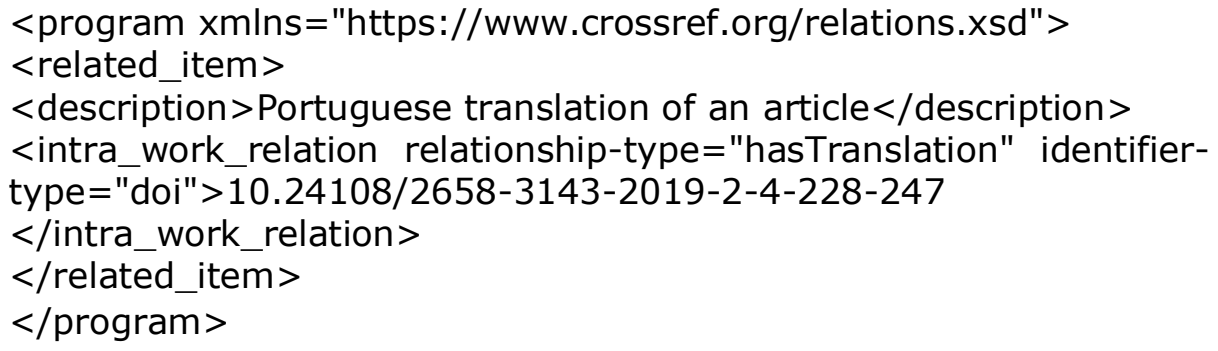

Рис. 8. Пример установления ссылки между оригиналом и переводом в XML

"relation": \{"is-translation-of": [ \{"id-type": "doi",

"id":"10.7717\/peerj.4375", "asserted-by":"subject"\} ], "cites": [] \}

"relation": \{ "has-review": [

\{"id-type": "doi","id":"10.7287\/peerj.4375v0.1\/reviews $\backslash / 4 "$, "asserted-by": "object"\},

\{"id-type":"doi","id":"10.7287\/peerj.4375v0.1\/reviews $\backslash / 2 "$,

"asserted-by": "object"\},

\{"id-type":"doi","id":"10.7287\/peerj.4375v0.1\/reviews \/3",

"asserted-by": "object"\},

\{"id-type": "doi","id":"10.7287\/peerj.4375v0.1\/reviews \/1",

"asserted-by": "object" \},

$\{$ "id-type":"doi","id":"10.7287\/peerj.4375v0.2\/reviews \/3",

"asserted-by": "object"\},

\{"id-type":"doi","id":"10.7287\/peerj.4375v0.2\/reviews \/1",

"asserted-by": "object"\},

\{"id-type": "doi","id": "10.7287\/peerj.4375v0.2\/reviews \/2",

"asserted-by": "object"\}],

"has-translation": [ \{"id-type": "doi", "id":"10.24108/2658-3143-

2019-2-4-228-247", "asserted-by":"object"\}],"cites": [] \}

Рис. 9. Примеры установления ссылки между переводом и оригиналом в обе стороны. Источник: https://api.crossref.org/v1/works/10.7717/peerj.4375

(оригинал) и https://api.crossref.org/v1/works/10.24108/2658-3143-2019-2-4-228-247

(перевод).

Поскольку отношения указываются в метаданных для определенного DOI, их можно обновить и после публикации, по

${ }^{11}$ Мы попросили PEERJ добавить это отношение 15 мая 2020, но ответа пока не получили - потому пример показывает «как это должно выглядеть». Если кого-то интересует существующий пример - можно посмотреть

https://api.crossref.org/v1/works/10.17537/2017.12.102 
аналогии с обновлением URL статьи, если журнал меняет веб сайт. То есть во всех приведенных выше примерах, издательства, издающие переводную версию могут добавить отношение isTranslationOf, a издательства, издающие версию-оригинал использовать отношение hasTranslation. Более того, в случае наличия таблицы соответствий, как в примере с MathNet.Ru, оба издателя могут использовать эту таблицу при регистрации отношений в CrossRef.

Мы считаем, что использование таких стандартных отношений при регистрации DOI для научных статей является первым шагом на пути построения таблицы соответствий, которая станет стандартом во всех дисциплинах и продолжит отдельные успешные начинания, рассмотренные выше. Более того, это позволяет не только корректировать библиометрические показатели, но и избегать возможных нарушений публикационной этики.

\section{4 Что дальше?}

В этой статье мы рассмотрели несколько существующих вариантов публикаций статей на нескольких языках и предложили универсальное решение. Хотя мы рассматривали решение на примерах из научных журналов, оно может применяться и к другим типам научных документов в Crossref: книжным главам (book chapters) и статьям в материалах конференций (conference paper). Это позволит решить похожие проблемы в случае перевода книг и статей. Например, конференция «Суперкомпьютерные дни в России» публикует часть материалов на русском ${ }^{12}$, а часть - на английском ${ }^{13}$. Используя решение, описанное в этой статье, можно переводить лучшие статьи на английский и корректно привязывать их к русским версиям. Аналогично с книжными главами английская версия учебника [6] является дополненным переводом [7]. Если какие-то главы переведены полностью - это можно указать.

В данной работе мы не рассматривали ссылки на уровне журналов. В примерах 2.3 и 2.4 фактически мы имеем дело с 2 разными журналами (в каждом примере) издаваемыми разными

\footnotetext{
12 https://elibrary.ru/item.asp?id=30632199

13 https://doi.org/10.1007/978-3-319-71255-0
} 
издательствами. Ссылки между ними указываются либо на сайте журнала, либо через ISSN-реестр. К сожалению, рассмотренные примеры не являются образцами для подражания, т.к. в ISSNреестре ссылки между версиями отсутствуют. Более того, если сравнивать информацию на сайте журнала и в каталоге Crossref ${ }^{14}$, издатели указаны по-разному. В примере 2.3 и 2.4 на сайтах это ИКЦ "Академкнига" и ООО «Функциональные наноматериалы», а в Crossref: Akademizdatcenter Nauka и National University of Science and Technology MISiS, соответственно.

Еще встречаются журналы, которые публикуют статьи на нескольких языках, как например «JALT, Journal of the Japan Association for Language Teaching ${ }^{15}$ », который публикует статьи на японском и английском. В этом случае отсутствуют проблемы этических нарушений или учёта цитирования.

В заключение хотелось бы упомянуть, что проблемы публикации на нескольких языках не являются специфически российскими или пост-советскими проблемами. Однако на данным момент, мы не располагаем примерами, как эти проблемы решает Китай, Южная Корея, Япония, Италия, Бразилия, Хорватия, Германия, несмотря на то что первый автор обсудил проблему с коллегами, которые ведут программы журналов из Южной Кореи, Китая и Японии в Springer Nature. Во всех трех программах журналы публикуемые Springer Nature являются международными журналами издаваемыми на английском языке (хотя и с сильной привязкой к определенной стране), а не переводными.

\section{5 Благодарности}

Авторы благодарят Ольгу Владимировну Кириллову, Jörg Schreiber, Felix Bock, Tom Spicer, Joyce Li, Takeyuki Yonezawa, Patricia Feeney и Geoffrey Bilder за консультации по теме статьи.

\section{References}

1.[1] Кириллова О.В. О влиянии языка статей на показатели научных журналов в международных наукометрических базах данных. Научный редактор и издатель. 2019;4(1-2):21-33. https://doi.org/10.24069/2542-0267-2019-1-2-21-33

\footnotetext{
14 https://www.crossref.org/06members/50go-live.html. Список префиксов Crossref.

15 https://jalt-publications.org/jj/issues/2019-05_41.1
} 
2.[2] Аксентьева, М. С., Кириллова, О. В., \& Москалева, О. В. (2013). К вопросу цитирования в Web of Science и Scopus статей из российских журналов, имеющих переводные версии. Научная периодика: проблемы и решения, 4 (16), 4-18. https://doi.org/ $10.18334 / \mathrm{np} 3496$

3.[3] Teixeira da Silva, J.A. The ethics of publishing in two languages. Scientometrics 123, 535541 (2020). https://doi.org/10.1007/s11192-020-03363-2

4.[4] Chebukov D.E., Izaak A.D., Misyurina O.G., Pupyrev Y.A., Zhizhchenko A.B. (2013) Math-Net.Ru as a Digital Archive of the Russian Mathematical Knowledge from the XIX Century to Today. CICM 2013. Lecture Notes in Computer Science, vol 7961. Springer, Berlin, Heidelberg. https://doi.org/10.1007/978-3-642-39320-4 26

5.[5] Crossref medatata. Content registration, structural metadata. Example: translated article. https://www.crossref.org/education/content-registration/structural-metadata/\#00047, проверено 2020/05/01.

6.[6] Kurgalin S., Borzunov S. (2018) The Discrete Math Workbook. Springer, Cham.

7.[7] Борзунов С.В., Кургалин С.Д. (2016) Задачи по дискретной математике. BHV. 